\title{
Adsorption of Nitrogen Monoxide and Carbon Monoxide on Copper-Exchanged ZSM-5: A Cluster and Embedded Cluster Study
}

\author{
Piti Treesukol,,$+\star$ Jumras Limtrakul, ${ }^{\ddagger}$ and Thanh N. Truong $*, \dagger$ \\ Henry Eyring Center for Theoretical Chemistry, Department of Chemistry, University of Utah, 315 S. 1400 E., \\ rm. 2020, Salt Lake City, Utah 84112, and Department of Chemistry, Faculty of Science, Kasetsart University, \\ Jatujak, Bangkok 10900, Thailand
}

Received: November 22, 2000; In Final Form: January 17, 2001

\begin{abstract}
We present a systematic study on the adsorption of $\mathrm{NO}$ and $\mathrm{CO}$ in $\mathrm{Cu}-\mathrm{ZSM}-5$, using an ab initio embedded cluster methodology at the B3LYP level of theory. We found that the effects of the cluster size and Madelung potential are small for adsorption energies of $\mathrm{CO}$ and $\mathrm{NO}$. For adsorption of $\mathrm{CO}$, the calculated binding energy of $32 \mathrm{kcal} / \mathrm{mol}$ is in good agreement with experimental data from 29 to $32 \mathrm{kcal} / \mathrm{mol}$. On the contrary, for adsorption of NO the calculated binding energy of $22 \mathrm{kcal} / \mathrm{mol}$ is much smaller than the experimental estimate, though it is consistent with recent experimental observation that NO binding energy should be smaller than that of CO. Madelung potential, however, is important for obtaining the correct blue shift of an adsorbed $\mathrm{CO}$ and red shift of an adsorbed $\mathrm{NO}$.
\end{abstract}

\section{Introduction}

$\mathrm{Cu}-\mathrm{ZSM}-5$ has been the subject of many recent theoretical and experimental studies since it was discovered to thermally and photoactivated catalyze the reduction of $\mathrm{NO}_{x}$ species. ${ }^{1-7}$ The adsorption of NO molecules on the active site to form nitrosyl complexes is considered the important step. Much progress in understanding the nature of the active site of the $\mathrm{Cu}$-ZSM-5 zeolite has been made. However, a detailed molecular-level understanding of the mechanism of catalytic reduction of $\mathrm{NO}_{x}$ species is far from complete.

XANES, EXAFS, and photoluminescence showed that $\mathrm{Cu}(\mathrm{I})$ species are the active site for the decomposition of $\mathrm{NO},{ }^{8-12}$ and almost all of $\mathrm{Cu}$ (II) ions in $\mathrm{Cu}-\mathrm{ZSM}-5$ can be autoreduced to $\mathrm{Cu}(\mathrm{I})$ ions during an evacuation process. ${ }^{9} \mathrm{CO}$ has been frequently used as a probe molecule to obtain information about the active sites of $\mathrm{Cu}-\mathrm{ZSM}-5$ due to its high IR absorbance intensity and the stability of the $\mathrm{Cu}-\mathrm{ZSM}-5 / \mathrm{CO}$ complexes. ${ }^{10,13-15}$ $\mathrm{CO}$ is known to be adsorbed on $\mathrm{Cu}-\mathrm{ZSM}-5$, even under mild conditions such as at low pressure and room temperature. ${ }^{16-23}$ The frequency shift of $\mathrm{CO}$ in the adsorption complex has been used to depict the characteristic of the active site and its bonding nature. At least two types of $\mathrm{Cu}(\mathrm{I})$ species had been identified from previous IR experiments. ${ }^{16,17,24}$ The first $\mathrm{Cu}(\mathrm{I})$ species bonds symmetrically to two framework oxygen atoms, and the other bonds asymmetrically to three framework oxygen atoms. Those results agree with XAFS, IR, and UV-vis spectroscopy studies, which showed that the average coordination number of $\mathrm{Cu}(\mathrm{I})$ is $2.5 \pm 0.3 .^{8-11,25}$ Experimental observations suggested that the first $\mathrm{Cu}(\mathrm{I})$ type is an active site for the $\mathrm{NO}_{x}$ adsorption, but both types are required for the $\mathrm{NO}_{x}$ decomposition process.

Numerous theoretical models have also been performed to provide information on the nature of the active site of $\mathrm{Cu}-$ ZSM-5. Several models of the active site have been proposed from the simplest model, in which a $\mathrm{Cu}$ cation is in fixed-

* Corresponding author, truong@ chemistry.utah.edu.

$\dagger$ University of Utah.

$\doteqdot$ Kasetsart University. coordination with water ligands $\left(\mathrm{Cu}^{+}\left[\mathrm{H}_{2} \mathrm{O}\right]_{n}\right),{ }^{26-28}$ to more realistic ones which consist of up to six tetrahedral sites. ${ }^{18,29-35}$ As discussed below, these models have some mix success. Furthermore, although its coordination information has been established, the location of $\mathrm{Cu}^{+}$in the zeolite framework is not known for certain. Previous HF and lattice energy minimizing calculations showed that $\mathrm{T} 12$ is the most stable site for $\mathrm{Al}$ substitution and is believed to be the type I active center. ${ }^{36,37}$ Such a site is reasonable from the structural point of view, since the bridging oxygens adjacent to the $\mathrm{T} 12$ site protrude into the intersection of main and sinusoidal channels; thus, this site provides sufficient space for small adsorbates binding to the exchanged copper ion. ${ }^{38}$ For this reason, most previous theoretical works have chosen T12 as the active site's center. However, using a more accurate combined quantum/potential methodology, Sauer and co workers showed that T12 is not the most stable site for $\mathrm{Al},{ }^{39}$ though it is among the more stable sites and there are only negligible differences in the relative energies of these sites. This issue certainly requires further study.

Understanding the adsorption of $\mathrm{CO}$ and $\mathrm{NO}$ on $\mathrm{Cu}-\mathrm{ZSM}-5$ zeolite would be the first step in studying the catalytic activity of this zeolite. Experimentally, the $2156-2157 \mathrm{~cm}^{-1}$ band was attributed to the stretching frequency of adsorbed $\mathrm{CO}$ on the $\mathrm{Cu}(\mathrm{I})$ site. ${ }^{9,15,17,24,40}$ Kuroda deconvoluted this peak into two dominant peaks at 2159 and $2151 \mathrm{~cm}^{-1}$, which were assigned to the stretching frequencies of $\mathrm{CO}$ adsorbed at $\mathrm{Cu}(\mathrm{I})$ species binding to two and three oxygen atoms, respectively. When $\mathrm{Cu}-$ ZSM-5 is exposed to NO gas, there are three bands appearing via IR at 2295,1630 , and $1812 \mathrm{~cm}^{-1}$. The first two bands occur due to spontaneous decomposition of $\mathrm{NO}$, and the last band was attributed to $\mathrm{NO}$ adsorbing on the $\mathrm{Cu}^{+}$site. ${ }^{8,9,16,41,42}$ The experimental binding energies of $\mathrm{CO}$ and $\mathrm{NO}$ largely depend on many factors, e.g., the $\mathrm{Si} / \mathrm{Al}$ ratio, the $\mathrm{Cu}$ exchanged rate, temperature, and pressure. The relative binding energy between $\mathrm{CO}$ and $\mathrm{NO}$ is still questionable. However, recent IR and adsorption experiments suggested that $\mathrm{CO}$ molecules bind to $\mathrm{Cu}-\mathrm{ZSM}-5$ zeolite stronger than NO molecules. ${ }^{24,43}$ Adsorption of $\mathrm{CO}$ and $\mathrm{NO}$ have also been the subject of numerous 
theoretical studies. ${ }^{18,27-30,34,35,44-50}$ The calculated results for adsorption energy, frequency shift, geometry, and the coordination number are still scattered due to differences in the topological structure of the model, cluster size, constraints, basis sets, and the levels of theory employed. Almost all of the previous theoretical models, except the $\mathrm{Cu}$-water cluster, were not able to predict the experimental blue shift of adsorbed $\mathrm{CO}$. Although the simplest $\mathrm{Cu}^{+}\left[\mathrm{H}_{2} \mathrm{O}\right]_{n}$ model was able to illustrate several important characteristics of the active site, including the frequency shift of adsorbed $\mathrm{CO}$, the predicted $\mathrm{NO}$ and $\mathrm{CO}$ binding energies are far below the experimental heat of adsorption values. ${ }^{51}$

One of the most important characteristics of zeolite is its complicated framework comprising of channels and pores. The simplest approximation is to only consider the active site locally and ignore the environment effects of the zeolite framework, as in the cluster model. However, there is sufficient evidence that such environment effects are significant., ${ }^{5,5,52,53}$ For instance, the framework of ZSM-5 significantly enhances the catalytic property of $\mathrm{Cu}-\mathrm{ZSM}-5$ over other $\mathrm{Cu}$-exchanged zeolites. So we cannot refute the important role of the zeolite framework in this catalytic process. From a computational point of view, to account for the effects of the zeolite framework in the study of adsorption or reactions in zeolites has been a great challenge. The large unit cells of most zeolites, such as 288 atoms for the ZSM-5, prevent the use of an accurate periodic electronic-structure method, though some progress has been made in this direction, but at a great computational cost. ${ }^{54-61}$ It should be noted that periodic calculations correspond to high loading (coverage) cases.

A practical approach to account for the crystal effects of the zeolite is to embed the quantum mechanical cluster model of the active site in a classical potential field due to the extended zeolite framework. There are two embedding approaches. One is referred to as the electronic embedding method, which includes the electrostatic interactions of the infinite lattice of zeolite in the Fock matrix of a quantum mechanic cluster. ${ }^{62-66}$ The other is referred to as the mechanical embedding method, which represents with an analytical force field the potential from the crystal environment and the active site is treated as a quantum mechanical cluster. ${ }^{45,39,67,68}$ Although there are some differences in these two approaches, both have been successfully applied to studying adsorptions and reactions in zeolites. It is interesting to note that to date there has not been a systematic theoretical study focusing on the dependence of $\mathrm{NO}$ and $\mathrm{CO}$ adsorption properties on models of the active site, i.e., cluster size, Madelung potential, levels of theory.

From a theoretical point of view, to gain a qualitative understanding on the adsorption of small molecules on metalexchanged zeolite, one first needs to have some knowledge on the model dependence of adsorption properties of interest. In this study, our main objectives are (1) to provide a better understanding of the cluster and embedded cluster computational methodology in the study of adsorption/reaction in metalexchanged zeolites and (2) to predict adsorption properties for adsorption of $\mathrm{NO}$ and $\mathrm{CO}$ on $\mathrm{Cu}-\mathrm{ZSM}-5$ zeolite. The focus of our first objective is on the cluster size dependence and the effects of the Madelung potential on the NO/CO adsorption properties. This is accomplished by carrying out both cluster and embedded cluster calculations for different quantum clusters representing the active center. The focus of our second objective is on the adsorption structures, energies, and frequency shifts of the NO/CO adsorbed complexes. The results of this study are important for establishing a cost-effective methodology for future studies on the mechanisms of both thermal and photoactivated catalytic reductions of $\mathrm{NO}_{x}$ by $\mathrm{Cu}-\mathrm{ZSM}-5$ and other metal-exchanged -ZSM-5 zeolites.

\section{Methodology}

The ZSM-5 structure was taken from the silicious ZSM-5 crystal (Figure 1a). ${ }^{69}$ To represent the Lewis basic active site, the silicon atom of the T12 site was substituted by an aluminum atom. Note that we selected the T12 site for this study for the reason discussed above. $\mathrm{An} \mathrm{Cu}(\mathrm{I})$ ion was added to counterbalance the negative charge of $\left[\mathrm{AlO}_{4}\right]^{-}$. The exchanged monovalent copper ion was chosen to bind to two framework oxygen atoms (corresponding to the I2 site in ref 39), protruding in to the channel intersection as an initial guess structure.

Four clusters ranging from $3 \mathrm{~T}$ to $10 \mathrm{~T}$, where $\mathrm{T}$ is $\mathrm{Si}-$ or Altetrahedral $\left(\mathrm{SiO}_{4}\right.$ or $\left.\mathrm{AlO}_{4}{ }^{-}\right)$, were cut from the ZSM-5 lattice. The largest cluster, [ $\left.\mathrm{AlSi}_{9} \mathrm{O}_{16} \mathrm{H}_{20}\right]^{-} \mathrm{Cu}^{+}$, is a complete 10membered-ring cluster of the main channel of ZSM-5 (Figure 1b). This model represents the zeolite's pore structure, enclosing an active site and adsorbates. The other clusters are 7T, 5T, and $3 \mathrm{~T}$ that have molecular structures of $\left[\mathrm{AlSi}_{6} \mathrm{O}_{12} \mathrm{H}_{16}\right]^{-} \mathrm{Cu}^{+}$, $\left[\mathrm{AlSi}_{4} \mathrm{O}_{10} \mathrm{H}_{12}\right]^{-} \mathrm{Cu}^{+}$, and $\left[\mathrm{AlSi}_{2} \mathrm{O}_{8} \mathrm{H}_{8}\right]^{-} \mathrm{Cu}^{+}$, respectively (see Figures $1 \mathrm{c}-\mathrm{e}$ ). Due to the partial covalent nature of zeolite, the boundary Si atoms of each cluster were saturated by capped hydrogen atoms located along the broken $\mathrm{Si}-\mathrm{O}$ bonds in ZSM-5 lattice with an $\mathrm{Si}-\mathrm{H}$ bond distance of $1.47 \AA$. The boundary $\mathrm{SiH}_{3}$ groups were held fixed in all geometry optimizations.

To incorporate the environmental effects of the remaining zeolite framework, the QM clusters are embedded in a potential field of point charges. The SCREEP method was used to construct these point charges. The detailed description of the SCREEP method was previously discussed elsewhere. ${ }^{64}$ To account for the electrostatic potential from the capped hydrogen atoms and to minimize their interactions with the external point charges, we removed the first shell of external charges closest to the QM cluster and adjusted the charge's values of the next shell to reproduce the correct classical Madelung potential calculated from the Ewald-sum method in the active site region.

Nonlocal hybrid density functional theory, particularly the B3LYP functional, was used in this study due to its consistency and reliability in zeolite systems. ${ }^{31,34,45,66,70}$ For practical purpose, we employed a larger basis set for the active site region, [SiOAlOSi] ${ }^{-} \mathrm{Cu}^{+}$, namely, the 6-31G(d) basis set for $\mathrm{Si}, \mathrm{Al}, \mathrm{O}$, and the adsorbate; the HayWadt-VDZ ${ }_{n+1}$ ECP basis set for $\mathrm{Cu}(\mathrm{I})$ ion; and the smaller $3-21 \mathrm{G}$ basis set for the remaining spectator region.

Preliminary calculations for the smaller embedded model confirmed the experimental observation that adsorptions of $\mathrm{CO}$ and NO do not have large effects on the structure of the zeolite framework. ${ }^{51,66}$ Thus, to reduce the computational demand the active site and the surrounding sites, except those of the $\mathrm{SiH}_{3}$ boundary groups, were allowed to fully relax in both cluster and embedded cluster calculations and then were held fixed in subsequent NO/CO adsorption calculations. All calculations were done using the Gaussian98 program. $^{71}$

\section{Results and Discussion}

In this study, we have examined both the physical properties of $\mathrm{CO}$ and $\mathrm{NO}$ adsorptions on $\mathrm{Cu}-\mathrm{ZSM}-5$ zeolite and the factors that can affects the accuracy of the embedded cluster model, particularly the size of the quantum cluster and the Madelung potential. Thus it is natural to separate the discussion of the results into two parts, namely, model dependence and chemistry of $\mathrm{CO}$ and $\mathrm{NO}$ adsorption on $\mathrm{Cu}-\mathrm{ZSM}-5$ zeolite. 
a

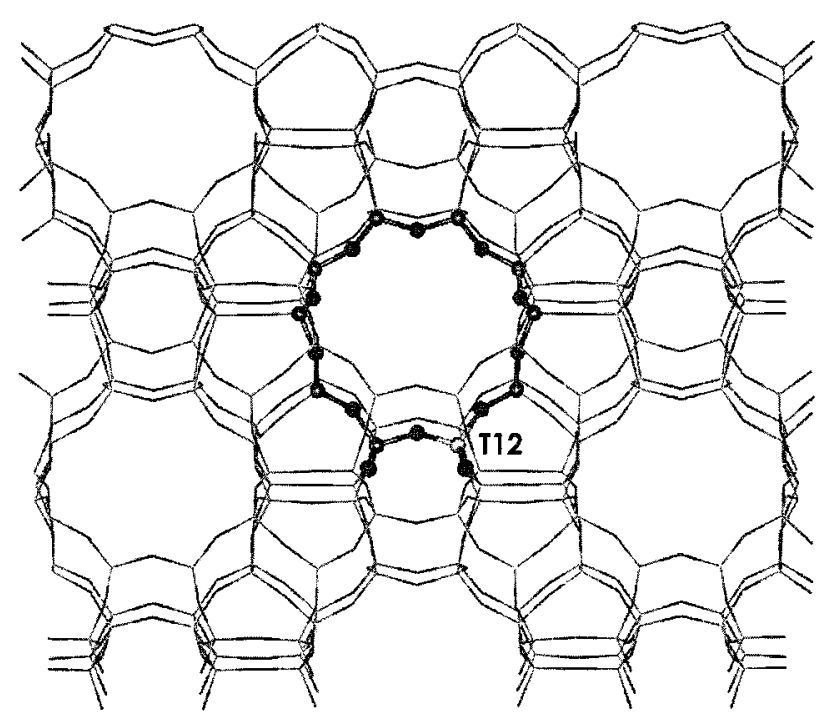

c

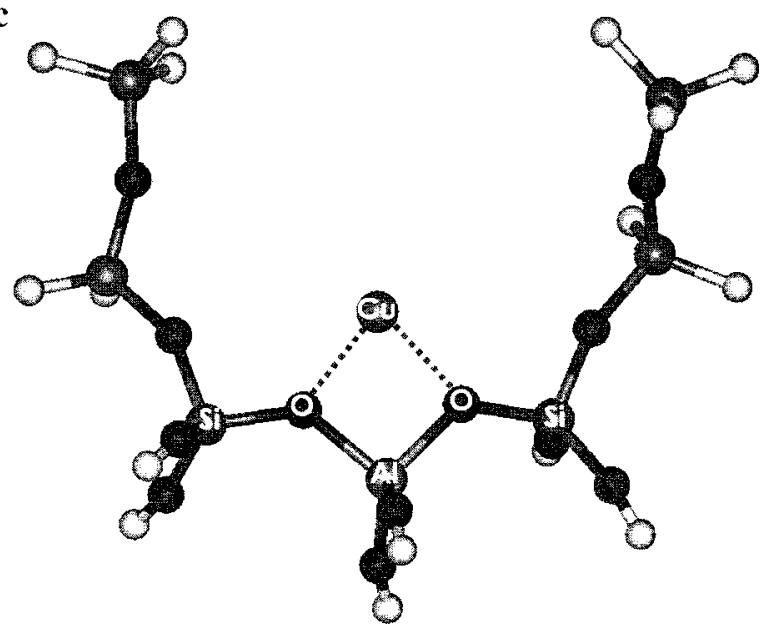

b

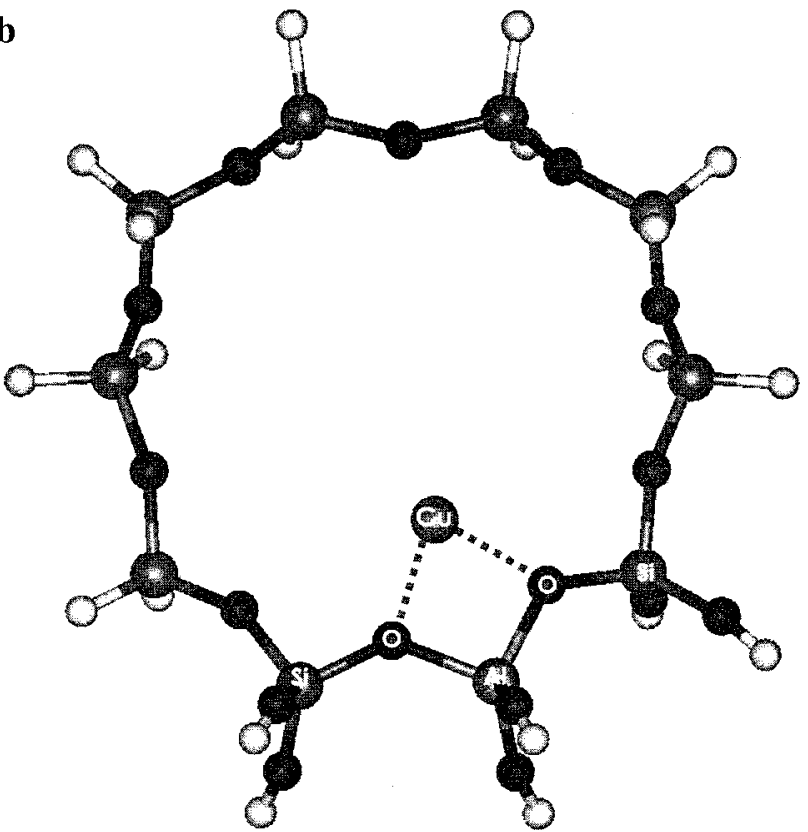

$\mathbf{d}$

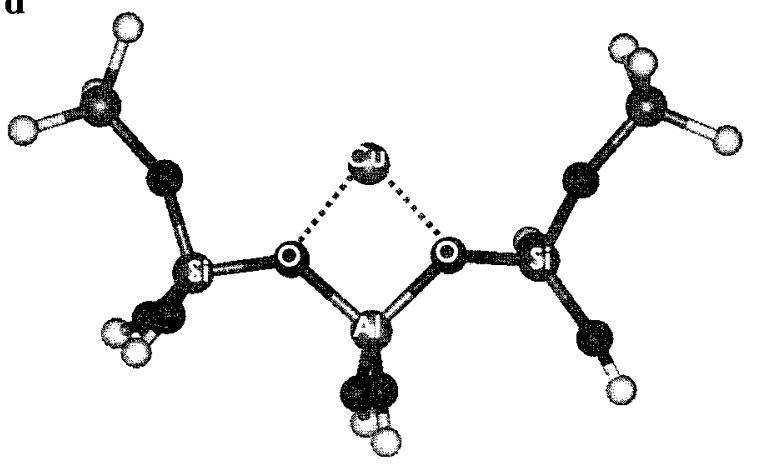

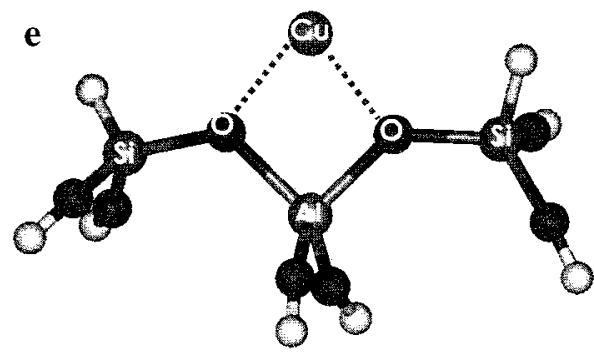

Figure 1. Cu-ZSM-5 Cluster models: (a) ZSM-5 lattice, (b) 10T cluster, (c) $7 \mathrm{~T}$ cluster, (d) $5 \mathrm{~T}$ cluster, and (e) $3 \mathrm{~T}$ cluster of Cu-ZSM-5.

Our calculated results are summarized in Tables 1-3. Optimized geometrical parameters, Mulliken charges, and $\mathrm{Cu}$ ion binding energy of $\mathrm{Cu}-\mathrm{ZSM}-5$ calculated from both the cluster and embedded cluster methods using four different QM clusters are tabulated in Table 1. Similar results for $\mathrm{CO}$ and $\mathrm{NO}$ adsorption on $\mathrm{Cu}-\mathrm{ZSM}-5$ are listed in Tables 2 and 3, respectively.

Model Dependence. In the embedded cluster methodology, there are two main factors that can affect the accuracy of the results, namely, the size of the QM cluster and the representation of the embedded potential. It is difficult to separate the effects of these two factors. In this study, the embedding potential consists of only the long-range electrostatic contribution from the zeolite framework. As the size of the QM cluster increases, it includes the short-range electrostatic, repulsion-dispersion, and polarization contributions from the local region of the active site in its full quantum mechanical treatment. Thus, the most accurate results from this study are from the embedded 10T cluster calculations and are used as a reference point for comparison in the discussion of model dependence.

Cu-ZSM-5 Active Site. We found that the local structure of the active site, i.e., the $\mathrm{Cu}^{+}$ion binding site, is not very sensitive to the size of the QM cluster and the inclusion of the Madelung potential. As the size of the QM cluster increases from $3 \mathrm{~T}$ to $10 \mathrm{~T}$, the $\mathrm{Cu}-\mathrm{O}$ bond distances increase by at most $0.01 \AA$ and the $\mathrm{Al}-\mathrm{O}$ (to $\mathrm{O} 1$ or $\mathrm{O} 2$ ) bond distances decrease by at most $0.05 \AA$. The $\mathrm{Cu}-\mathrm{Al}$ distance appears to converge at 
TABLE 1: Structural Parameters (̊̊), Mulliken Charges (au), and Binding Energy (kcal/mol) of Cu-ZSM-5 Clusters

\begin{tabular}{|c|c|c|c|c|c|c|c|c|c|c|c|c|}
\hline \multirow[b]{2}{*}{ MFI } & \multicolumn{3}{|c|}{$3 \mathrm{~T}$} & \multicolumn{3}{|c|}{$5 \mathrm{~T}$} & \multicolumn{3}{|c|}{$7 \mathrm{~T}$} & \multicolumn{3}{|c|}{$10 \mathrm{~T}$} \\
\hline & bare & $\mathrm{emb}^{a}$ & $\mathrm{emb}^{b}$ & bare & $\mathrm{emb}^{a}$ & $\mathrm{emb}^{b}$ & bare & $\mathrm{emb}^{a}$ & $\mathrm{emb}^{b}$ & bare & $\mathrm{emb}^{a}$ & $\mathrm{emb}^{b}$ \\
\hline $\mathrm{Cu}-\mathrm{O}^{c}$ & 1.980 & & 2.003 & 1.990 & & 2.006 & 1.994 & & 2.012 & 1.998 & & 2.013 \\
\hline $\mathrm{Cu}-\mathrm{O} 2^{c}$ & 1.993 & & 2.005 & 2.010 & & 2.016 & 2.011 & & 2.023 & 2.012 & & 2.032 \\
\hline $\mathrm{Cu}-\mathrm{Al}$ & 2.743 & & 2.767 & 2.725 & & 2.748 & 2.732 & & 2.758 & 2.732 & & 2.764 \\
\hline $\mathrm{Al}-\mathrm{O} 1$ & 1.812 & & 1.819 & 1.752 & & 1.760 & 1.752 & & 1.755 & 1.751 & & 1.753 \\
\hline $\mathrm{Al}-\mathrm{O} 2$ & 1.780 & & 1.785 & 1.748 & & 1.757 & 1.747 & & 1.748 & 1.748 & & 1.745 \\
\hline$q(\mathrm{Cu})$ & 0.52 & 0.61 & 0.61 & 0.52 & 0.57 & 0.58 & 0.49 & 0.55 & 0.55 & 0.48 & 0.55 & 0.55 \\
\hline$q(\mathrm{O})$ & -0.60 & -0.60 & -0.59 & -0.60 & -0.60 & -0.60 & -0.60 & -0.60 & -0.59 & -0.60 & -0.60 & -0.60 \\
\hline$E_{\text {bind }}(\mathrm{Cu})^{d}$ & 180.13 & & 233.76 & 184.02 & & 195.62 & 185.76 & & 180.05 & 187.30 & & 163.90 \\
\hline
\end{tabular}

${ }^{a}$ Unoptimized embedded cluster. ${ }^{b}$ Optimized embedded cluster. ${ }^{c}$ Framework oxygens. ${ }^{d}$ Includes BSSE correction.

TABLE 2: Structural Parameters ( $\AA$ and deg), Mulliken Charges (au), and Binding Energy (kcal/mol) of CO Adsorption on Cu-ZSM-5 Clusters

\begin{tabular}{|c|c|c|c|c|c|c|c|c|c|c|}
\hline \multirow[b]{3}{*}{ parameters $^{a}$} & \multirow{3}{*}{$\frac{\mathrm{Cu}(\mathrm{I})}{\frac{\mathrm{C}-\text { down }}{\text { cluster }}}$} & \multicolumn{3}{|c|}{$3 \mathrm{~T}$} & \multirow{2}{*}{\multicolumn{2}{|c|}{$\begin{array}{c}5 \mathrm{~T} \\
\text { C-down }\end{array}$}} & \multirow{2}{*}{\multicolumn{2}{|c|}{$\frac{7 \mathrm{~T}}{\mathrm{C} \text {-down }}$}} & \multirow{2}{*}{\multicolumn{2}{|c|}{$\frac{10 \mathrm{~T}}{\mathrm{C} \text {-down }}$}} \\
\hline & & \multirow{2}{*}{$\frac{\text { O-down }}{\text { emb }}$} & \multicolumn{2}{|c|}{ C-down } & & & & & & \\
\hline & & & cluster & $\mathrm{emb}$ & cluster & $\mathrm{emb}$ & cluster & emb & cluster & $\mathrm{emb}$ \\
\hline $\mathrm{CO}^{b}$ & 1.126 & 1.139 & 1.137 & 1.136 & 1.138 & 1.134 & 1.138 & 1.135 & 1.137 & 1.136 \\
\hline $\mathrm{Cu} \cdots \mathrm{C}(\mathrm{O})$ & 1.893 & $2.002^{e}$ & 1.818 & 1.827 & 1.815 & 1.829 & 1.817 & 1.829 & 1.825 & 1.832 \\
\hline$\angle \mathrm{Cu} \cdots \mathrm{CO}$ & 179.9 & $175.9^{f}$ & 179.8 & 178.8 & 180.0 & 178.6 & 178.2 & 174.7 & 178.6 & 177.8 \\
\hline$q(\mathrm{CO})$ & 0.26 & 0.13 & 0.22 & 0.25 & 0.23 & 0.25 & 0.23 & 0.25 & 0.23 & 0.24 \\
\hline$q(\mathrm{Cu})$ & 0.74 & 0.54 & 0.36 & 0.43 & 0.33 & 0.37 & 0.30 & 0.36 & 0.29 & 0.37 \\
\hline$q\left(\mathrm{O}_{z}\right)^{c}$ & & -0.60 & -0.60 & -0.60 & -0.60 & -0.60 & -0.60 & -0.60 & -0.60 & -0.60 \\
\hline$E_{\text {bind }}{ }^{d}$ & 57.50 & 6.18 & 32.58 & 32.21 & 32.53 & 32.83 & 32.98 & 33.13 & 31.69 & 32.30 \\
\hline
\end{tabular}

${ }^{a}$ Only the adsorbate is optimized. ${ }^{b}$ Optimized gas-phase CO bond length is $1.138 \AA .{ }^{c}$ Average of charges on two bridging oxygen atoms. ${ }^{d}$ Include BSSE and ZPE corrections. ${ }^{e} \mathrm{Cu} \cdots \mathrm{O}(\mathrm{C})$ distance. ${ }^{f} \angle \mathrm{Cu} \cdots \mathrm{OC}$.

TABLE 3: Structural Parameters ( $₫$ and deg), Mulliken Charges (au), and Binding Energy (kcal/mol) of NO Adsorption on Cu-ZSM-5 Clusters

\begin{tabular}{|c|c|c|c|c|c|c|c|c|c|c|}
\hline \multirow[b]{3}{*}{ parameters $^{a}$} & \multirow{3}{*}{$\frac{\mathrm{Cu}(\mathrm{I})}{\frac{\mathrm{N}-\text { down }}{\text { cluster }}}$} & \multicolumn{3}{|c|}{$3 \mathrm{~T}$} & \multirow{2}{*}{\multicolumn{2}{|c|}{$\frac{5 \mathrm{~T}}{\mathrm{~N}-\text { down }}$}} & \multirow{2}{*}{\multicolumn{2}{|c|}{$\frac{7 \mathrm{~T}}{\mathrm{~N} \text {-down }}$}} & \multirow{2}{*}{\multicolumn{2}{|c|}{$\frac{10 \mathrm{~T}}{\mathrm{~N}-\text { down }}$}} \\
\hline & & \multirow{2}{*}{$\frac{\text { O-down }}{\text { emb }}$} & \multicolumn{2}{|c|}{ N-down } & & & & & & \\
\hline & & & cluster & emb & cluster & emb & cluster & emb & cluster & emb \\
\hline $\mathrm{NO}^{b}$ & 1.147 & 1.174 & 1.168 & 1.166 & 1.169 & 1.164 & 1.168 & 1.165 & 1.167 & 1.165 \\
\hline $\mathrm{Cu} \cdots \mathrm{N}(\mathrm{O})$ & 1.871 & $1.952^{e}$ & 1.815 & 1.822 & 1.814 & 1.826 & 1.815 & 1.823 & 1.821 & 1.824 \\
\hline$\angle \mathrm{Cu}{ }^{\cdots} \cdot \mathrm{NO}$ & 179.9 & $138.1^{f}$ & 145.4 & 145.4 & 144.8 & 144.8 & 145.3 & 147.6 & 148.0 & 148.3 \\
\hline$q(\mathrm{NO})$ & 0.12 & 0.10 & 0.08 & 0.11 & 0.09 & 0.13 & 0.09 & 0.13 & 0.10 & 0.12 \\
\hline$q(\mathrm{Cu})$ & 0.88 & 0.54 & 0.45 & 0.52 & 0.43 & 0.45 & 0.40 & 0.44 & 0.38 & 0.46 \\
\hline$q\left(\mathrm{O}_{z}\right)^{c}$ & & -0.59 & -0.59 & -0.59 & -0.59 & -0.59 & -0.59 & -0.59 & -0.59 & -0.59 \\
\hline$E_{\text {bind }} d$ & 42.94 & 7.32 & 23.38 & 22.84 & 23.66 & 22.80 & 23.92 & 23.47 & 22.61 & 21.78 \\
\hline
\end{tabular}

${ }^{a}$ Only the adsorbate is optimized. ${ }^{b}$ Optimized gas-phase NO bond length is $1.159 \AA .{ }^{c}$ Average of charges on two bridging oxygen atoms. ${ }^{d}$ Include BSSE and ZPE corrections. ${ }^{e} \mathrm{Cu} \cdots \mathrm{O}(\mathrm{N})$ distance. ${ }^{f} \angle \mathrm{Cu} \cdots \mathrm{ON}$.

7T. Examining the convergence of the structural parameters, we found that the $3 \mathrm{~T}$ cluster results deviate noticeable from others, thus indicating such a cluster is too small. Inclusion of the Madelung potential increases all $\mathrm{Cu}-\mathrm{O}, \mathrm{Al}-\mathrm{O}$, and $\mathrm{Cu}-$ Al bond distances. The largest variation of about $0.03 \AA$ is in the $\mathrm{Cu}-\mathrm{Al}$ bond distance. The increase in the $\mathrm{Cu}-\mathrm{Al}$ bond distance would hinder the delocalization of $\mathrm{Cu}^{+}$charge by the zeolite framework. This observation is further supported by the larger $\mathrm{Cu}$ Mulliken charge (by $0.1 \mathrm{au}$ ) when the Madelung potential is included (see Figure 2). Note that increasing the cluster size in bare cluster calculations does not have such an effect. Thus, the $\mathrm{Cu}^{+}$charge localization is due mainly to the Madelung potential. The $\mathrm{Cu}^{+}$binding energy shows the largest dependence on both the QM cluster size and the Madelung potential. From the bare cluster calculations, the $\mathrm{Cu}^{+}$binding energy increases from 180.1 to $187.3 \mathrm{kcal} / \mathrm{mol}$ when the size of the QM cluster increases from $3 \mathrm{~T}$ to $10 \mathrm{~T}$. The embedded calculations show the reverse trend, i.e., the binding energy decreases from 233.8 to $163.9 \mathrm{kcal} / \mathrm{mol}$ from the $3 \mathrm{~T}$ to the $10 \mathrm{~T}$ case. This indicates that inclusion of only the long-range Madelung potential may overestimate the $\mathrm{Cu}^{+}$binding energy. The local short-range repulsion dispersion and polarization of

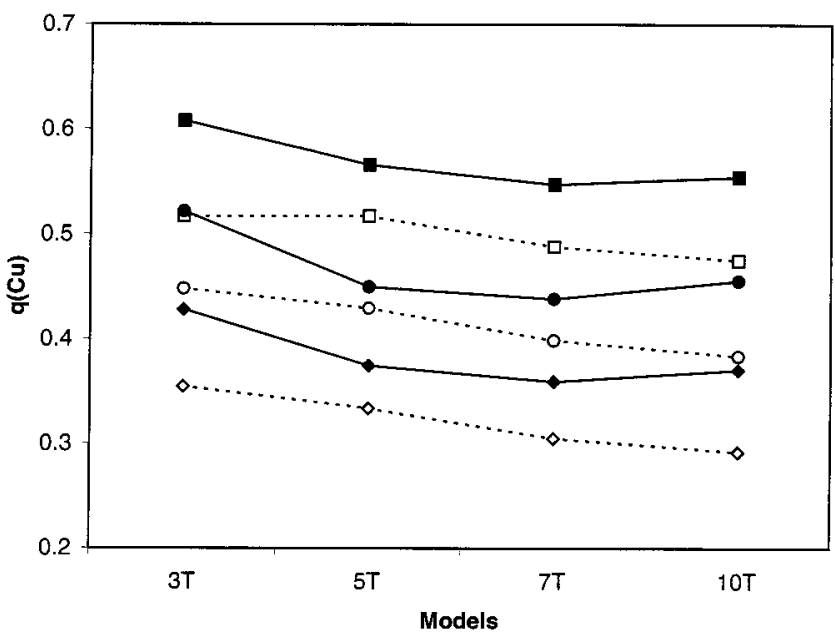

Figure 2. The cluster size and the Madelung potential dependences of the $\mathrm{Cu}$ Mulliken charge: cluster $(\square)$, embedded cluster ( $\mathbf{\square}), \mathrm{CO} /$ cluster $(\mathrm{O}), \mathrm{CO} /$ embedded cluster $(\bullet)$, $\mathrm{NO} /$ cluster $(\diamond)$, and $\mathrm{NO} /$ embedded cluster $(\bullet)$.

the zeolite framework also have a noticeable contribution in lowering the ion binding energy. 
CO and NO Adsorption. Both $\mathrm{CO}$ and NO may bind to a $\mathrm{Cu}$ ion of $\mathrm{Cu}-\mathrm{ZSM}-5$ via either the $\mathrm{C}-$ (or $\mathrm{N}-$ ) down or the O-down structures. The results are shown in Tables 2 and 3. We have used both bare and embedded $3 \mathrm{~T}$ cluster models to investigate both modes of adsorption for $\mathrm{CO}$ and $\mathrm{NO}$ on $\mathrm{Cu}-$ ZSM-5. For both systems, the $\mathrm{Cu}-\mathrm{O}$ binding distances ( $\mathrm{Cu}$ to oxygen of $\mathrm{CO}$ or $\mathrm{NO}$ ) in the O-down adsorption complexes are more than $0.13 \AA$ longer than the corresponding C-down or $\mathrm{N}$-down case. Consequently, the O-down adsorption complexes have much weaker binding energies, particularly 6.2 versus 33.2 $\mathrm{kcal} / \mathrm{mol}$ for the $\mathrm{CO} / \mathrm{Cu}-\mathrm{ZSM}-5$ complex and 7.3 versus 22.8 $\mathrm{kcal} / \mathrm{mol}$ for the NO/Cu-ZSM-5 complex. For this reason, we do not expect that the O-down adsorption mode would play an important role in the chemistry of reduction of $\mathrm{NO}_{x}$ by $\mathrm{Cu}-$ ZSM-5 zeolite, and thus, we only concentrate our further efforts to study the $\mathrm{C}$-down and $\mathrm{N}$-down adsorption modes.

It is interesting to note that the structures and binding energies for adsorption of both $\mathrm{CO}$ and $\mathrm{NO}$ on $\mathrm{Cu}-\mathrm{ZSM}-5$ zeolite do not depend strongly on either the cluster size or the Madelung potential. In fact, variations in the $\mathrm{CO}$ and $\mathrm{NO}$ bond distances in the adsorption complexes are less than $0.005 \AA$ for both bare and embedded cluster methods. Inclusion of the Madelung potential is seen to lengthen the adsorption distance $(\mathrm{Cu}-\mathrm{N}$ or $\mathrm{Cu}-\mathrm{C}$ bond distance) by at most $0.015 \AA$. Similar to the $\mathrm{Cu}-$ ZSM-5 zeolite, in the adsorption complexes, the Madelung potential localizes the $\mathrm{Cu}^{+}$ion charge but to a lesser degree. Both the effects of the QM cluster size and the Madelung potential give rise to the variations in the $\mathrm{CO}$ binding energy from 31.7 to $33.2 \mathrm{kcal} / \mathrm{mol}$ and in the NO binding energy from 21.8 to $23.9 \mathrm{kcal} / \mathrm{mol}$. It is interesting to point out the general perception that the Madelung potential tends to increase the binding energy of the adsorbate. It is not so. Our results show that the Madelung potential increases the CO binding energy by about $1 \mathrm{kcal} / \mathrm{mol}$ but decreases the NO binding energy also by about $1 \mathrm{kcal} / \mathrm{mol}$. Although the effect of the Madelung potential is not large here, it is sufficient to illustrate the point.

In summary, with the exception of the $\mathrm{Cu}^{+}$ion binding energy, the structures of the $\mathrm{Cu}-\mathrm{ZSM}-5$ and its $\mathrm{CO}$ and $\mathrm{NO}$ adsorption complexes and their corresponding binding energies exhibit a rather weak dependence on the size of the quantum cluster and the inclusion of the Madelung potential. The Madelung potential, however, was found to stabilize the $\mathrm{Cu}^{+}$ ion charge and thus reduces the charge delocalization by the zeolite framework. This would have an important implication in studying the photocatalytic activity of metal-exchanged zeolites where the charge-transfer process is thought to be an important step in the catalytic cycle. From the variations in the structures, binding energies, and Mulliken charges, we found that the embedded $5 \mathrm{~T}$ cluster model provides a balance between computational efficiency and accuracy.

Chemistry. In this subsection, we discuss the chemistry of $\mathrm{CO}$ and $\mathrm{NO}$ adsorption on $\mathrm{Cu}-\mathrm{ZSM}-5$ and comparisons of our results with those from previous experimental and other theoretical studies. For this, we use the results from our most accurate embedded 10T cluster calculation.

Cu-ZSM-5. Previous experimental and theoretical studies have suggested that $\mathrm{Cu}^{+}$ions are located at intersections between sinusoidal and main channels, exposed to diffused species. The majority of $\mathrm{Cu}^{+}$ions in ZSM-5 are expected to coordinate to two bridging oxygen atoms of the active site. ${ }^{18,29,30,33,45,50,72}$ All structural parameters of our model, i.e., bond distances and the coordination number of the copper ion, are comparable to experimental results. Particularly, the calculated $\mathrm{Cu}-\mathrm{O}$ bond distances of $2.013-2.032 \AA$ (see Table 1) are in excellent agreement with the experimental data of $2.00 \pm 0.02 \AA$, determined by Lamberti et al. ${ }^{8}$ In comparison with previous theoretical studies, our calculated $\mathrm{Cu}-\mathrm{O}$ bond distances are slightly larger. In particular, Chakraborty et al., ${ }^{33}$ using the $5 \mathrm{~T}$ cluster, found the two $\mathrm{Cu}-\mathrm{O}$ bond lengths of 1.95 and $1.86 \AA$. The DFT/LSD calculations of Hass and Schneider on the 5T cluster yielded $\mathrm{Cu}-\mathrm{O}$ distances of 1.919 and $1.924 \AA .30$ Increasing cluster size and including the Madelung potential do not have large effects, though they bring the results in better agreement with experimental values. Although there is some charge redistribution between the copper ion and zeolite framework, the charge of 0.55 on the $\mathrm{Cu}^{+}$ion supports the suggestion that these $\mathrm{Cu}^{+}$ions prefer to exist as isolated monomer species. ${ }^{73}$

Since experimental data for the $\mathrm{Cu}^{+}$binding energy is not available, we compare our results to previous theoretical data. We mentioned above that the binding energy between the $\mathrm{Cu}^{+}$ cation and zeolite framework shows a strong dependence on the cluster size and the Madelung potential. Comparisons with previous studies further support this conclusion and also show some dependence on the levels of theory employed. In particular, Hass and Schneider used the simple 5T model at the DFT/LSDA level of theory and obtained the binding energy of $175 \mathrm{kcal} /$ mol. ${ }^{29}$ Sauer and co-workers ${ }^{45}$ determined the $\mathrm{Cu}^{+}$binding energy of $160 \mathrm{kcal} / \mathrm{mol}$ from a $3 \mathrm{~T}$ model at the DFT/B3LYP level of theory. Sauer et al. ${ }^{39}$ also predicted a value of 148.6 $\mathrm{kcal} / \mathrm{mol}$ from their mechanical embedded 3T cluster model (QM-pot) at the same level of theory. Our calculated binding energy with the basis set superposition error (BSSE) correction is $164 \mathrm{kcal} / \mathrm{mol}$. The variations in these results serve as a caution for the use of cluster and embedded cluster models in studying Lewis basic sites and adsorption of ions on zeolites.

Adsorption of $\mathrm{CO}$ on $\mathrm{Cu}-\mathrm{ZSM}-5$. Basically, the nature of the bonding between $\mathrm{a} \mathrm{Cu}^{+}$ion and a $\mathrm{CO}$ molecule can be described by the back-bonding process. The HOMO orbital of $\mathrm{CO}$ is the $5 \sigma^{*}$ antibonding orbital. $\sigma$ donation from this orbital to the transition metal ion would strengthen both the $\mathrm{CO}$ bond and the $\mathrm{Cu} \cdot \mathrm{CO}$ interaction. On the other hand, the LUMO of $\mathrm{CO}$ is the $6 \pi^{*}$ orbital. $\pi$ accepting to this orbital, i.e., electron flows from the transition metal to the $6 \pi^{*}$ orbital, would strengthen the $\mathrm{Cu}+\mathrm{CO}^{\mathrm{CO}}$ interaction but weaken the $\mathrm{CO}$ bond.

$\mathrm{CO}$ bond length is shortened slightly upon adsorption. Our calculated $\mathrm{Cu}-\mathrm{O}_{\text {framework }}$ and $\mathrm{Cu} \cdots \mathrm{C}$ distances of 2.03 and 1.832 $\AA$ are in excellent agreement with those of 2.05 and $1.89 \AA$ determined by Nagao et al. ${ }^{51}$ using spectroscopic techniques. As expected, the $\mathrm{Cu} \cdots \mathrm{C}$ bond is slightly affected by the Madelung potential, thus supporting the observation that the $\mathrm{Cu} \cdots \mathrm{C}$ stretching frequency is much more sensitive to the zeolite structure, i.e., the long-range potential, than the $\mathrm{CO}$ bonding. ${ }^{15}$ The $\mathrm{Cu}{ }^{\cdots} \mathrm{CO}$ angle is linear (Figure 3 ) corresponding to previous calculation studies. ${ }^{26,27,30}$ The net charge of the adsorbed $\mathrm{CO}$ molecule is slightly positive, revealing the electron transfer from an adsorbate to the copper ion. From the shortening of the $\mathrm{CO}$ bond length and the decreasing of the $\mathrm{Cu}^{+}$positive charge, we can conclude that the $\sigma$ donating dominates the interaction between the exchanged copper and the carbonyl ligand.

One of the most important characteristics of the $\mathrm{CO} / \mathrm{Cu}-$ ZSM-5 complex that can be obtained from experiment is the IR frequency of adsorbed $\mathrm{CO}$. While the interaction between the bare $\mathrm{Cu}^{+}$ion and a $\mathrm{CO}$ molecule yields the red shift of the $\mathrm{CO}$ stretching frequency, IR spectra of adsorption of $\mathrm{CO}$ on $\mathrm{Cu}-\mathrm{ZSM}-5$ yields two peaks (from two different $\mathrm{Cu}^{+}$sites as mentioned above) at 2159 and $2151 \mathrm{~cm}^{-1}$, which are blueshifted from the peak at $2143 \mathrm{~cm}^{-1}$ of the gas-phase $\mathrm{CO}^{24}$ This 


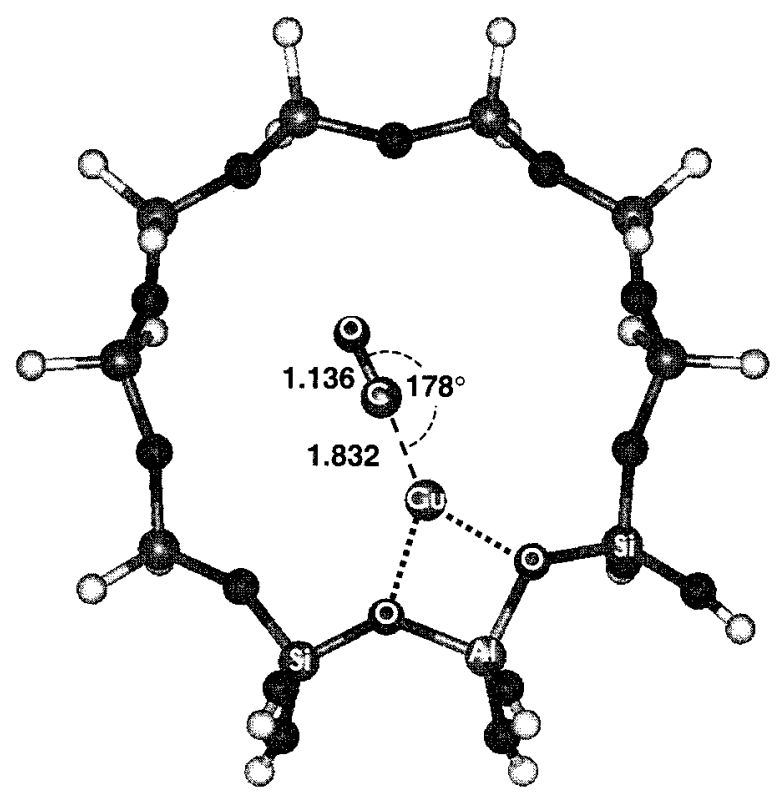

Figure 3. Optimized structure of $\mathrm{CO} / \mathrm{Cu}-\mathrm{ZSM}-5$ complex using the embedded 10T model.

blue shift should correspond to the stronger and shorter $\mathrm{CO}$ bond, as observed in this study. To confirm this the stretching frequency of an adsorbed $\mathrm{CO}$ was calculated using our embedded 3T model. Without any scaling, the adsorbed CO frequency was determined to be $2237.7 \mathrm{~cm}^{-1}$, blue-shifted from 2208.2 $\mathrm{cm}^{-1}$ of the gas-phase CO. Such a blue shift was not observed in most of the previous theoretical models, even at the same cluster size and the same level of calculation. Thus the Madelung potential is expected to be important for obtaining the correct blue shift of an adsorbed CO.

The binding energies calculated from previous theoretical models are quite scattered, ranging from 25 to $54 \mathrm{kcal} /$ mol. ${ }^{27,29,30,46,74}$ The experimental CO binding energy was determined to be $28.7 \mathrm{kcal} / \mathrm{mol}$ by Nagao et al. ${ }^{51}$ and $31.6 \mathrm{kcal} /$ mol by Szanyi and Paffett (an unpublished result cited by Brand et al. ${ }^{27}$ ). After including the BSSE correction and zero-point energy (ZPE) correction, we obtain the CO binding energy of $32.01 \mathrm{kcal} / \mathrm{mol}$, which agrees well with experimental values.

In this study, we found an "anticorrelation" between binding energy and bond distance. If the bonding between an ion and an adsorbate is dominated by electrostatic interaction, one can expect that the binding energy decreases upon increasing the bond distance. Our results show that while the binding energy between the bare $\mathrm{Cu}^{+}$ion with $\mathrm{CO}(57.5 \mathrm{kcal} / \mathrm{mol})$ is much larger than that $(32.3 \mathrm{kcal} / \mathrm{mol})$ of the $\mathrm{Cu}-\mathrm{ZSM}-5 / \mathrm{CO}$ complex, the $\mathrm{Cu} \cdots \mathrm{C}$ bond distance is longer, $1.893 \AA$ compared to 1.832 $\AA$. This indicates that the interactions between the $\mathrm{Cu}^{+}$site in ZSM-5 zeolite and CO are more complex than just an electrostatic one. This supports the previous suggestion that the combination of electrostatic interaction, between $\mathrm{CO}$ molecule and zeolitic framework, and $\sigma$ donation, between $\mathrm{CO}$ and exchanged copper ion, induces a blue shift of adsorbed CO. ${ }^{75}$

\section{Adsorption of NO on Cu-ZSM-5.}

The HOMO of NO molecule is the $6 \pi^{*}$ orbital. The electron transfer from the copper's d-orbital to this orbital in the $\pi$ accepting process increases the $\mathrm{Cu}^{+}{ }^{+} \mathrm{NO}$ interaction but simultaneously decreases the NO bond order, i.e., elongates the NO bond distance while the $\pi$ and $\sigma$ donating (from $5 \sigma^{*}$ and $6 \pi^{*}$ orbitals) would increase the $\mathrm{Cu}^{+} \ldots \mathrm{NO}$ interaction and $\mathrm{NO}$ bond order, i.e., shorten the NO bond distance.

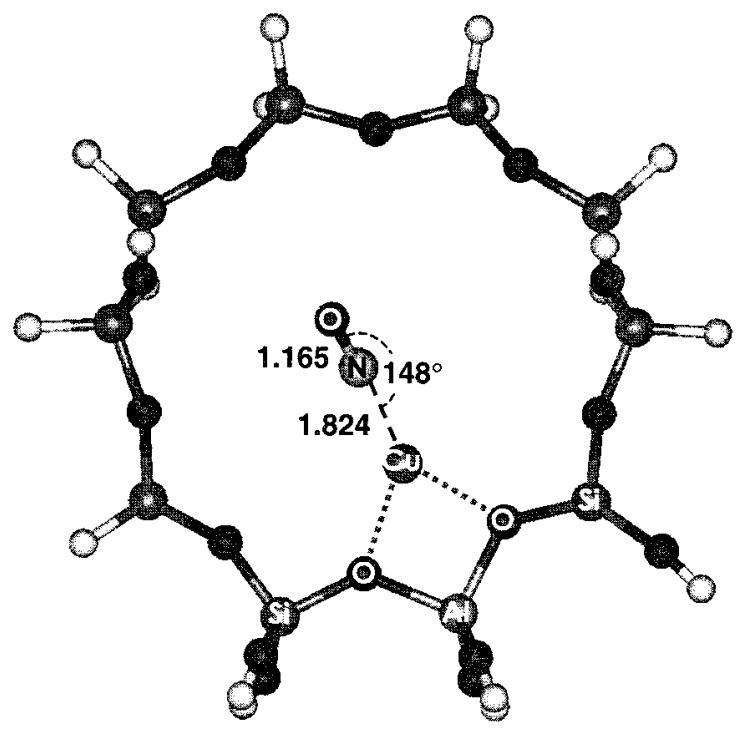

Figure 4. Optimized structure of $\mathrm{NO} / \mathrm{Cu}-\mathrm{ZSM}-5$ complex using the embedded 10T model.

Our calculated $\mathrm{NO}$ bond distance in the $\mathrm{NO} / \mathrm{Cu}-\mathrm{ZSM}-5$ complex is $1.165 \AA$, which is longer than the gas-phase value of $1.159 \AA$. Previous theoretical studies have also observed this elongation of the NO bond. This indicates that $\pi$ accepting is the dominant process, which is opposite of the $\mathrm{CO} / \mathrm{Cu}-\mathrm{ZSM}-5$ case. It is interesting to point out that for the bare $\mathrm{Cu}^{+}$ion/NO complex, the NO bond distance is shortened to $1.147 \AA$ and thus $\sigma$ donating is preferred (molecular charge of adsorbed NO compared to free NO). These results show that the zeolite framework is important in determining the nature of the bonding between the exchanged $\mathrm{Cu}^{+}$ion and the adsorbate. From IR studies, the NO stretching vibration at $1810 \mathrm{~cm}^{-1}$ was assigned to linearly adsorbed $\mathrm{NO}$, since generally $\mathrm{NO}$ frequencies that are larger than $1720 \mathrm{~cm}^{-1}$ correspond to linear species. ${ }^{18,76,77}$ Our $\mathrm{Cu}^{\cdots} \mathrm{NO}$ angle of $148^{\circ}$ (see Figure 4) differs drastically from this suggestion and also from the $\mathrm{CO} / \mathrm{Cu}-\mathrm{ZSM}-5$ case (see Figure 3 ). This appears to be a contradiction between our result and experiment. Since the interaction between the $\mathrm{Cu}^{+}$ion and NO is dominated by the $\pi$ accepting, one can expect that the $\mathrm{Cu} \cdots \mathrm{NO}$ configuration should be bent to have a positive overlap with Cu's d orbital (the linear configuration would yield zerooverlap). This is different from the $\mathrm{CO} / \mathrm{Cu}-\mathrm{ZSM}-5$ system, where the $\sigma$ donating is the dominant process and the linear configuration would have the largest overlap. To further understand the difference between our result and the experimental observation, we plotted a potential curve as the function of the $\mathrm{Cu} \cdots \mathrm{NO}$ angle, as shown in Figure 5. From the overlap argument above one can expect the linear configuration to be the saddle point between the two symmetrical bent structures. Figure 5 confirms our expectation, and the barrier for converting between the two stable bent structures is only $1 \mathrm{kcal} / \mathrm{mol}{ }^{26}$ This suggests that experiments would observe the average of the thermal fluctuation between the two stable bent structures, i.e., the linear configuration. Thus, our results provide a deeper understanding of the adsorption structure of NO on $\mathrm{Cu}-\mathrm{ZSM}-5$.

The NO stretching frequency of the NO/Cu-ZSM-5 complex, observed experimentally at $1812 \mathrm{~cm}^{-1}$, is red-shifted from 1860 $\mathrm{cm}^{-1}$ of the gas-phase NO. ${ }^{42}$ This red shift corresponds to the lengthening of the NO bond, observed in our study and other theoretical works. ${ }^{27,29,32,46,47}$ The stretching frequency of an adsorbed NO was calculated using our embedded $3 \mathrm{~T}$ model to be $1921.7 \mathrm{~cm}^{-1}$, red-shifted from $1990.4 \mathrm{~cm}^{-1}$ of the gas-phase NO. 


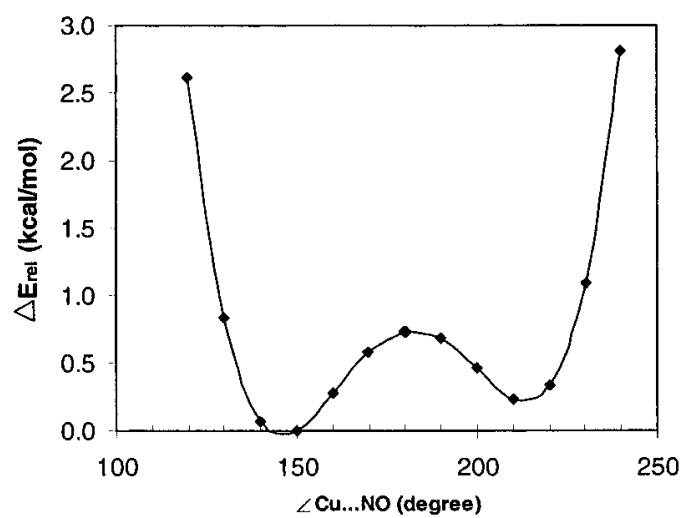

Figure 5. Potential energy curve, relative to the stable $\mathrm{NO} / \mathrm{Cu}-\mathrm{ZSM}-5$ complex as a function of $\mathrm{Cu} \cdot \cdot \mathrm{NO}$ angle.

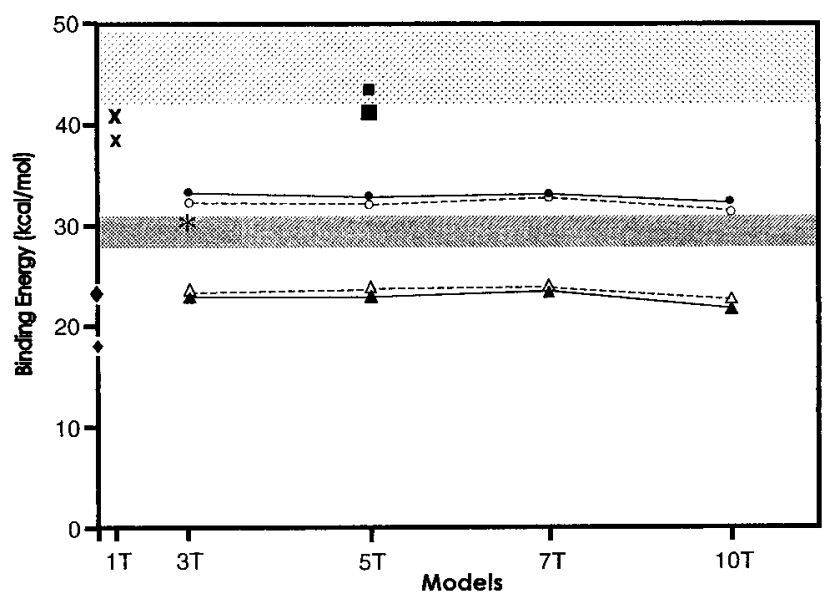

Figure 6. Comparison between calculated and experimental binding energies, for the $\mathrm{CO} / \mathrm{Cu}-\mathrm{ZSM}-5$ system: the present embedded results (upper solid line), bare cluster results (upper dashed line), experimental range (light shade area, from refs 27 and 51), and previous theoretical predictions (large $\checkmark$ from ref 27; large $\mathbf{x}$ from ref 46; large $\mathbf{\square}$ from ref $30)$. For the $\mathrm{NO} / \mathrm{Cu}-\mathrm{ZSM}-5$ system: the present embedded results (lower solid line), bare cluster results (lower dashed line), experimental range (dark shade area, from ref 18) and previous theoretical predictions (small $\bullet$ from ref 27; small $\mathbf{x}$ from ref 46 ; small $\boldsymbol{\square}$ from ref 30 and $*$ from ref 79).

Our calculated binding energy of NO to the $\mathrm{Cu}-\mathrm{ZSM}-5$, including the BSSE and ZPE corrections, is about $22 \mathrm{kcal} / \mathrm{mol}$. Note that previous calculated binding energies of $\mathrm{NO}$ adsorption are very scattered, ranging from 17 to $52 \mathrm{kcal} / \mathrm{mol}$, as shown in Figure 6. ${ }^{18,29,30,34,44,46,47,78,79}$ The NO binding energy estimated by Chakraborty et al. ${ }^{18}$ from TPD results of Li and Armor is 43.9-49.5 kcal/mol and that estimated from Schay and Guczi's results is $47.6-49.5 \mathrm{kcal} / \mathrm{mol}$. These experimental estimations are much higher than our prediction for the NO binding energy and higher than the experimental $\mathrm{CO}$ binding energy as well. However, recent experiments on successive adsorption of $\mathrm{CO}$ and $\mathrm{NO}^{15,16}$ found that $\mathrm{CO}$ molecules can displace $\mathrm{NO}$ molecules adsorbed on the active site of $\mathrm{Cu}-\mathrm{ZSM}-5$. This indicates that the binding energy of $\mathrm{NO}$ should be smaller than that of $\mathrm{CO}$ and thus supports our results. Note that our relative $\mathrm{CO} / \mathrm{NO}$ binding energies $(32.3 / 21.8 \mathrm{kcal} / \mathrm{mol})$ are consistent with those from the previous calculations of Schneider et al. (40.9/38.5 $\mathrm{kcal} / \mathrm{mol})^{26}$ and Brand et al. $(24.7 / 17.0 \mathrm{kcal} / \mathrm{mol}) .{ }^{27}$ Furthermore, the binding energy of $\mathrm{NO}$ to $\mathrm{Cu}-$ Zeolite-Y was determined to be $20 \mathrm{kcal} / \mathrm{mol}$ by IR spectroscopy, ${ }^{80}$ and a different absorption experiment also showed that $\mathrm{NO}$ can bind to the $\mathrm{Cu}-\mathrm{ZSM}-5$ tighter than to the $\mathrm{Cu}-$ Zeolite-Y. ${ }^{53}$ Due to the fact that Zeolite-Y and ZSM-5 have the same order of pore size, the binding energies of NO to these zeolites should not be too different. Combining all of these experimental facts, the NO binding energy should be slightly larger than $20 \mathrm{kcal} / \mathrm{mol}$ and thus fully consistent with our results.

\section{Conclusions}

We presented a systematic theoretical study on the structure of the Lewis basic active site of the $\mathrm{Cu}-\mathrm{ZSM}-5$ zeolite and the adsorption properties of $\mathrm{NO}$ and $\mathrm{CO}$ on this zeolite. Both cluster and embedded cluster methodologies were employed to study the effects of the cluster size and of the Madelung potential. From a theoretical point of view, we found that the effects of the cluster size and of the Madelung potential are small in the $\mathrm{NO}$ and $\mathrm{CO}$ adsorption properties. However, these effects are noticeable in the $\mathrm{Cu}^{+}$binding energy. Comparing all models considered in this study ranging from 3T to 10T, the $5 \mathrm{~T}$ cluster gives the optimal cost per performance ratio and thus provides a more practical model for future studies on this system. For NO and CO adsorption, we found that the zeolite framework plays a significant role in the adsorption mechanism. The calculated adsorption properties, namely, adsorption structure, binding energy, and vibrational frequency of $\mathrm{CO}$ on $\mathrm{Cu}-$ ZSM-5 zeolite, agree well with available experimental results. Compared to previous studies, the Madelung potential is expected to contribute the correct blue shift of an adsorbed $\mathrm{CO}$ and red shift of an adsorbed NO. Particularly, the calculated $\mathrm{CO}$ binding energy of $32.3 \mathrm{kcal} / \mathrm{mol}$ is in excellent agreement with the available experimental data from 29 to $32 \mathrm{kcal} / \mathrm{mol}$. For NO adsorption, we were able to explain to the difference between our predictions of the bent adsorption structure with the experimentally observed linear structure. The calculated NO binding energy of $21.8 \mathrm{kcal} / \mathrm{mol}$ is smaller than the estimated experimental values ranging from 44 to $50 \mathrm{kcal} / \mathrm{mol}$. However, our result is consistent with recent experimental observation that the NO binding energy should be smaller than that of $\mathrm{CO}$ and is within the range of $\mathrm{NO}$ binding energy in the similarly pore sized $\mathrm{Cu}-\mathrm{Y}$ zeolite. The calculated red shift in the adsorbed NO stretching frequency also agrees well with experiments.

The study further supports the use of the embedded cluster model to study adsorption in zeolites, particularly metalexchanged zeolites, and establishes a foundation for future studies of the catalytic activity of $\mathrm{Cu}-\mathrm{ZSM}-5$ in reduction of $\mathrm{NO}_{x}$ species.

Acknowledgment. This work is supported in part by the Royal Golden Jubilee Ph.D. project of Thailand, the University of Utah, and the National Science Foundation. The computer support from the Center of High Performance Computing at the University of Utah is gratefully acknowledged.

\section{References and Notes}

(1) Iwamoto, M.; Yahiro, H.; Tanda, K.; Mizuno, N.; Mine, Y.; Kagawa, S. J. Phys. Chem. 1991, 95, 3727.

(2) Sato, S.; Yoshihiro, Y.; Yahiro, H.; Mizuno, N.; Iwamoto, M. Appl. Catal. 1991, 70, L1.

(3) Shelef, M. Catal. Lett. 1992, 15, 305

(4) Li, Y. J.; Armor, J. N. Appl. Catal. 1991, 76, L1.

(5) Li, Y. J.; Hall, W. K. J. Catal. 1991, 129, 202.

(6) Armor, J. N. Catal. Today 1997, 38, 163.

(7) Anpo, M.; Matsuoka, M.; Hanou, K.; Mishima, H.; Yamashita, H.; Patterson, H. H. Coord. Chem. Rev. 1998, 171, 175.

(8) Lamberti, C.; Salvalaggio, M.; Bordiga, S.; Geobaldo, F.; Spoto, G.; Zecchina, A.; Vlaic, G.; Bellatreccia, M. J. Phys. IV 1997, 7, 905.

(9) Lamberti, C.; Bordiga, S.; Salvalaggio, M.; Spoto, G.; Zecchina, A.; Geobaldo, F.; Vlaic, G.; Bellatreccia, M. J. Phys. Chem. B 1997, 101, 344. 
(10) Bordiga, S.; Palomino, G. T.; Arduino, D.; Lamberti, C.; Zecchina, A.; Arean, C. O. J. Mol. Catal. A: Chem. 1999, 146, 97.

(11) Bordiga, S.; Lamberti, C.; Palomino, G. T.; Geobaldo, F.; Arduino, D.; Zecchina, A. Microporous Mesoporous Meter. 1999, 30, 129.

(12) Dedecek, J.; Wichterlova, B. Phys. Chem. Chem. Phys. 1999, 1 629 .

(13) Arean, C. O.; Palomino, G. T.; Zecchina, A.; Spoto, G.; Bordiga, S.; Roy, P. Phys. Chem. Chem. Phys. 1999, 1, 4139.

(14) Arean, C. O.; Tsyganenko, A. A.; Platero, E. E.; Garrone, E.; Zecchina, A. Angew. Chem., Int. Ed. 1998, 37, 3161.

(15) Borovkov, V. Y.; Jiang, M.; Fu, Y. L. J. Phys. Chem. B 1999 103,5010 .

(16) Kuroda, Y.; Kumashiro, R.; Yoshimoto, T.; Nagao, M. Phys. Chem. Chem. Phys. 1999, 1, 649.

(17) Kuroda, Y.; Mori, T.; Yoshikawa, Y.; Kittaka, S.; Kumashiro, R.; Nagao, M. Phys. Chem. Chem. Phys. 1999, 1, 3807.

(18) Trout, B. L.; Chakraborty, A. K.; Bell, A. T. J. Phys. Chem. 1996, 100, 17582

(19) Liu, D. J.; Robota, H. J. Catal. Lett. 1993, 21, 291.

(20) Dedecek, J.; Sobalik, Z.; Tvaruzkova, Z.; Kaucky, D.; Wichterlova, B. J. Phys. Chem. 1995, 99, 16327.

(21) Wichterlova, B.; Dedecek, J.; Vondrova, A. J. Phys. Chem. 1995, 99, 1065.

(22) Chen, L.; Chen, H. Y.; Lin, J.; Tan, K. L. Inorg. Chem. 1998, 37, 5294.

(23) Jang, H. J.; Hall, W. K.; Ditri, J. J. Phys. Chem. 1996, 100, 9416.

(24) Kuroda, Y.; Yoshikawa, Y.; Emura, S.; Kumashiro, R.; Nagao, M. J. Phys. Chem. B 1999, 103, 2155.

(25) Lamberti, C.; Spoto, G.; Scarano, D.; Paze, C.; Salvalaggio, M.; Bordiga, S.; Zecchina, A.; Palomino, G. T.; Dacapito, F. Chem. Phys. Lett. 1997, 269, 500 .

(26) Schneider, W. F.; Hass, K. C.; Ramprasad, R.; Adams, J. B. J. Phys. Chem. 1996, 100, 6032.

(27) Brand, H. V.; Redondo, A.; Hay, P. J. J. Phys. Chem. B 1997, 101,7691 .

(28) Ramprasad, R.; Schneider, W. F.; Hass, K. C.; Adams, J. B. J. Phys. Chem. B 1997, 101, 1940.

(29) Hass, K. C.; Schneider, W. F. J. Phys. Chem. 1996, 100, 9292

(30) Hass, K. C.; Schneider, W. F. Phys. Chem. Chem. Phys. 1999, 1 639.

(31) Rice, M. J.; Chakraborty, A. K.; Bell, A. T. J. Phys. Chem. A 1998, 102,7498 .

(32) Schneider, W. F.; Hass, K. C.; Ramprasad, R.; Adams, J. B. J. Phys. Chem. B 1997, 101, 4353.

(33) Trout, B. L.; Chakraborty, A. K.; Bell, A. T. J. Phys. Chem. 1996, $100,4173$.

(34) Yokomichi, Y.; Yamabe, T.; Ohtsuka, H.; Kakumoto, T. J. Phys. Chem. 1996, 100, 14424.

(35) Zhanpeisov, N. U.; Matsuoka, M.; Mishima, H.; Yamashita, H.; Anpo, M. THEOCHEM J. Mol. Struct. 1998, 454, 201.

(36) Derouane, E. G.; Fripiat, J. G. Zeolites 1985, 5, 165.

(37) Alvaradoswaisgood, A. E.; Barr, M. K.; Hay, P. J.; Redondo, A. J. Phys. Chem. 1991, 95, 10031.

(38) Spoto, G.; Zecchina, A.; Bordiga, S.; Ricchiardi, G.; Martra, G.; Leofanti, G.; Petrini, G. Appl. Catal., B 1994, 3, 151.

(39) Nachtigallova, D.; Nachtigall, P.; Sierka, M.; Sauer, J. Phys. Chem. Chem. Phys. 1999, 1, 2019.

(40) Sarkany, J. J. Mol. Struct. 1997, 410, 145.

(41) Wichterlova, B.; Dedecek, J.; Sobalik, Z.; Vondrova, A.; Klier, K. J. Catal. 1997, 169, 194.

(42) Aylor, A. W.; Larsen, S. C.; Reimer, J. A.; Bell, A. T. J. Catal. 1995, 157,592 .

(43) Valyon, J.; Hall, W. K. J. Catal. 1993, 143, 520

(44) Kanougi, T.; Tsuruya, H.; Oumi, Y.; Chatterjee, A.; Fahmi, A.;

Kubo, M.; Miyamoto, A. Appl. Surf. Sci. 1998, 132, 561.

(45) Rodriguez-santiago, L.; Sierka, M.; Branchadell, V.; Sodupe, M.; Sauer, J. J. Am. Chem. Soc. 1998, 120, 1545.

(46) Schneider, W. F.; Hass, K. C.; Ramprasad, R.; Adams, J. B. J. Phys. Chem. B 1998, 102, 3692.

(47) Kobayashi, H.; Ohkubo, K. Appl. Surf. Sci. 1997, 121, 111.
(48) Zhanpeisov, N. U.; Nakatsuji, H.; Hada, M.; Nakai, H.; Anpo, M. Catal. Lett. 1996, 42, 173

(49) Civalleri, B.; Garrone, E.; Ugliengo, P. J. Phys. Chem. B 1998, $102,2373$.

(50) Blint, R. J. J. Phys. Chem. 1996, 100, 19518

(51) Kumashiro, R.; Kuroda, Y.; Nagao, M. J. Phys. Chem. B 1999, 103,89 .

(52) Cheung, T.; Bhargava, S. K.; Hobday, M.; Foger, K. J. Catal. 1996, 158,301 .

(53) Valyon, J.; Hall, W. K. J. Phys. Chem. 1993, 97, 1204.

(54) Brandle, M. S. Joachim; Dovesi, Roberto; Harrison, Nicholas M. J. Chem. Phys. 1998, 109, 10379.

(55) Civalleri, B.; Zicovich-Wilson, C. M.; Ugliengo, P.; Saunders, V. R.; Dovesi, R. Chem. Phys. Lett. 1998, 292, 394.

(56) Hill, J.-R. F.; Clive, M.; Delley, B. J. Phys. Chem. A 1999, 103 3772 .

(57) Kessi, A.; Delley, B. Int. J. Quantum Chem. 1998, 68, 135.

(58) Nicholas, J. B.; Hess, A. C. J. Am. Chem. Soc. 1994, 116, 5428.

(59) Shah, R.; Payne, M. C.; Lee, M. H.; Gale, J. D. Science 1996, 271,1395

(60) Stich, I.; Gale, J. D.; Terakura, K.; Payne, M. C. J. Am. Chem. Soc. 1999, 121, 3292

(61) White, J. C.; Nicholas, J. B.; Hess, A. C. J. Phys. Chem. B 1997, 101,590 .

(62) Sherwood, P.; Devries, A. H.; Collins, S. J.; Greatbanks, S. P.; Burton, N. A.; Vincent, M. A.; Hillier, I. H. Faraday Discuss. 1997, 79.

(63) Greatbanks, S. P.; Hillier, I. H.; Sherwood, P. J. Comput. Chem. 1997, 18,562 .

(64) Stefanovich, E. V.; Truong, T. N. J. Phys. Chem. B 1998, 102 3018 .

(65) Vollmer, J. M.; Stefanovich, E. V.; Truong, T. N. J. Phys. Chem. B 1999, 103, 9415 .

(66) Limtrakul, J.; Khongpracha, P.; Jungsuttiwong, S.; Truong, T. N. J. Mol. Catal. A: Chem. 2000, 153, 155.

(67) Sierka, M.; Sauer, J. Faraday Discuss. 1997, 41.

(68) Sierka, M.; Sauer, J. J. Mol. Graph Model 1998, 16, 274.

(69) Insight II Release 95.0; BIOSYM/MSI: San Diego, 1995.

(70) Ferrari, A. M.; Neyman, K. M.; Rosch, N. J. Phys. Chem. B 1997, 101,9292

(71) Frisch, M. J.; Trucks, G. W.; H. B. Schlegel, G. E. S.; Robb, M A.; Cheeseman, J. R.; Zakrzewski, V. G.; Montgomery, J. A.; Stratmann, R. E.; Burant, J. C.; Dapprich, S.; Millam, J. M.; Daniels, A. D.; Kudin, K. N.; Strain, M. C.; Farkas, O.; Tomasi, J.; Barone, V.; Cossi, M.; Cammi, R.; Mennucci, B.; Pomelli, C.; Adamo, C.; Clifford, S.; Ochterski, J.; Petersson, G. A.; Ayala, P. Y.; Cui, Q.; Morokuma, K.; Malick, D. K.; Rabuck, A. D.; Raghavachari, K.; Foresman, J. B.; Cioslowski, J.; Ortiz, J. V.; Stefanov, B. B.; Liu, G.; Liashenko, A.; Piskorz, P.; Komaromi, I; Gomperts, R.; Martin, R. L.; Fox, D. J.; Keith, T.; Al-Laham, M. A.; Peng, C. Y.; Nanayakkara, A.; Gonzalez, C.; Challacombe, M.; Gill, P. M. W. Johnson, B. G.; Chen, W.; Wong, M. W.; Andres, J. L.; Head-Gordon, M. Replogle, E. S.; Pople, J. A. Gaussian 98 (Revision A.7); Pittsburgh, PA 1998.

(72) Yamashita, H.; Matsuoka, M.; Tsuji, K.; Sioya, Y.; Anpo, M.; Che, M. J. Phys. Chem. 1996, 100, 397.

(73) Yamashita, H.; Matsuoka, M.; Anpo, M.; Che, M. J. Phys. IV 1997, 7, 941 .

(74) Sengupta, D.; Schneider, W. F.; Hass, K. C.; Adams, J. B. Catal. Lett. 1999, 61, 179 .

(75) Scarano, D.; Bordiga, S.; Lamberti, C.; Spoto, G.; Ricchiardi, G.; Zecchina, A.; Arean, C. O. Surf. Sci. 1998, 411, 272.

(76) Aylor, A. W. L.; Sarah, C.; Reimer, J. A.; Bell, A. T. J. Catal. 1995, 157, 592 .

(77) Giamello, E.; D, M.; Magnacca, G.; Morterra, C.; Shioya, Y.; Nomura, T.; Anpo, M. J. Catal. 1992, 136, 510.

(78) Brand, H. V.; Redondo, A.; Hay, P. J. J. Mol. Catal. A: Chem. 1997, 121,45

(79) Tajima, N.; Hashimoto, M.; Toyama, F.; Elnahas, A. M.; Hirao,

K. Phys. Chem. Chem. Phys. 1999, 1, 3823.

(80) Davydov, A. A. Zh. Fiz. Khim. 1991, 65, 269. 